\title{
UNA VISIÓN ANTROPOLÓGICAMENTE RELIGIOSA
}

\author{
AN ANTHROPOLOGICALLY RELIGIOUS VIEW
}

Alejandro Frigerio ${ }^{1}$

No sé cuántas veces vi a Adalberto Pernambuco Nogueira, pero sé que fueron pocas - muchas menos de las que hubiera querido. Tengo dos recuerdos particularmente claros de su persona: el primero, de cuando se realizó en 1985 en Buenos Aires el Primer Congreso Argentino de Umbanda y sus Raíces, organizado por la Asociación Religiosa Africana Omio Babá, una casa de religión dirigida por la reconocida mãe argentina Peggie de Iemanjá. A esta primera reunión pública de practicantes de la religión en Argentina vino una delegación de pais de santo brasileros a participar de las disertaciones. Entre ellos, Adalberto Pernambuco Nogueira. Yo recién comenzaba mi trabajo de campo y recuerdo cómo rápidamente, con su sencillez, simpatía y don de gentes - y su gran conocimiento religioso - v se ganó el cariño de los participantes que siguieron con inusual interés su presentación. Días después, quien era mi principal "informante clave" en ese momento también se refirió elogiosamente a su persona. ${ }^{2}$ Algo inusual, ya que este pai tenía una rara y profunda formación religiosa para la época y miraba casi con desdén a la mayor parte de sus pares, a quienes casi ni reconocía como tales. Sobre Pernambuco, me dijo algo así como: "ese sí que sabe. Fue al único de los brasileros al que le pedí la bença, junto con José Mendes, que también es una persona extraordinaria".

Con ese antecedente en mi memoria, cuando unos años después Ari Oro me contó, durante una de mis visitas a Porto Alegre, que Adalberto quería

1 FLACSO-UCA/CONICET, Argentina. E-mail: alejandrofrig@yahoo.com.br

2 Cuando digo "informante clave", leáse: "el pai de santo que pacientemente me guió en mi camino desde una ignorancia basada apenas en conocimiento bibliográfico a un conocimiento más real y práctico que adquirí presenciando sesiones todas las semanas en su casa”. 
invitarme a su casa para que charláramos, acepté encantado. Creo que él aún se acordaba de mi tímida presentación en el congreso (una de mis primeras exposiciones públicas) y después, principalmente a través de Ari, supongo, habría seguido con alguna atención mis trabajos. Yo con certeza me acordaba de su presentación en Buenos Aires y del impacto que su presencia había causado localmente - ya no como un mero pai de santo brasilero de los muchos que venían a iniciar gente al país, sino como un referente religioso de otra estatura y densidad teológica y calidez humana.

Además de reconfirmarme personalmente y ya de manera más obvia los juicios positivos que me había hecho de sus personas unos años atrás, tengo otros dos recuerdo de nuestro encuentro en Porto Alegre que pueden parecer nimios pero que me llamaron mucho la atención en su momento. El primero y principal, de su gran biblioteca, en la cual cada libro había sido encuadernado en tapa dura, y en la que cada estante tenía no una sino dos filas de libros (una escondida detrás de la que se veía, porque el gran espacio de su departamento ya no era suficiente para tantos volúmenes). El segundo y ya más anecdótico, del (muy) fuerte café que me ofreció, del cual se enorgullecía y que ofrecía con generosidad. Recuerdo haber recibido, de boca de Ari, su cumplido a posteriori "sim, Frigerio, grande bebedor de cafe" - lo que suponía, espero, haber pasado el test del antropólogo visitante (o al menos, alguno de los varios que se nos hacen). Años después tuve la honra de ser convidado a uno de los encuentros anuales que organizaba en el auditorio de la Asamblea Legislativa local y siempre estuve al tanto, también por Ari, de sus múltiples actividades en defensa de las religiones afro en Rio Grande do Sul, y de la buena recepción que estas actividades tenían ante los poderes estatales y los representantes de otras religiones. Imagino, sin mucho esfuerzo, que sin su carisma personal y su perseverancia incansable, todo esto difícilmente habría ocurrido. Celebro que sus múltiples iniciativas le valieran el título de Cidadão de Porto Alegre, un justo reconocimiento a su obra y valía.

El buen provecho que hizo de su extensa biblioteca (que obviamente no estaba de adorno), y su contacto cercano con investigadores sobre religiones afrobrasileras de diversas generaciones se puede apreciar en estos textos que 
felizmente Debates do NER pone a nuestra disposición. Diría que su conocimiento y su aprecio - sin duda crítico - por los trabajos de los antropólogos o académicos de distinto tipo que se acercaron al batuque le brindan un carácter - digamos - anfibio a sus propios escritos. Tienen el conocimiento y la perspectiva religiosa de un pai de santo, pero toman en cuenta las circunstancias socio-históricas del desarrollo y la práctica de estas religiones como lo hacen los cientistas sociales. Es claro que no es el único líder religioso con una conciencia socio-histórica aguda (cada vez más pais y mães se han acercado a los estudios académicos) pero en alguien de su edad y en el momento en que los escribió era algo que resultaba bastante menos común.

Esto se evidencia claramente en el más extenso de estos textos en el cual realiza una interesante reseńa crítica sobre quienes investigaron las religiones afro-gaúchas, mostrando la manera en que sus proveniencias religiosas o disciplinarias (folklore, psicología, antropología) condicionaron su apreciación del objeto de estudio.

Es claro que no puedo concordar con su apreciación de que "faltaram-nos pesquisadores da competencia dos que estudaram a religiao nos estados de maior parte de escravos" y prefiero antes la explicación de que la atención prestada a la historia y la cultura afro en un estado cuya identidad se ha construído sobre lo gaúcho y lo europeo (como argumentó Ruben Oliven) necesariamente va a ser menor, o al menos mucho mas tardía que, en otros estados. Prueba de esto es el desinterés estatal del que fueron objeto, como señala Pernambuco, los archivos de algunos de los pesquisadores pioneros que menciona, y que llevó a su destrucción, pérdida o posible adquisición por otros estados. El mismo desinterés que sufrió su propia biblioteca a su fallecimiento, que inconcebiblemente no encontró institución que la acogiera.

Su condición de anfibio se manifiesta también en la reseña crítica que hace de los historiadores que brindan una visión poco real de la esclavitud, enfatizando los supuestos buenos tratos recibidos por los esclavizados, o exaltando la "democracia racial" regional.

Su doble condición de paiy (cuasi) académico se vislumbra, especialmente, en su descripción de las naciones del batuque. El concepto de nación tiene una 
gran importancia "nativa", es una identificación particularmente cargada de emotividad y que ubica al religioso dentro de un cierto linaje, y lo posiciona inequívocamente dentro del campo religioso afrobatuquero: se pertenece a determinado linaje y por él, a una determinada nación. En dos de los trabajos aquí presentados la descripción de las naciones ocupa un lugar relevante, pero es, a la vez, relativizado fácticamente, al decir que en realidad la mayor parte de las casas hacen los toques de la nación Ijexá. Su descripción, y bastantes partes del escrito, no dejan de recordarme los del recordado "maestro" bahiano Vivaldo da Costa Lima - quien era también sin duda un anfibio, sólo que desde otro lado: un académico con un profundo conocimiento de lo religioso y un compromiso que lo volvían prácticamente un nativo. ${ }^{3}$ Pernambuco, por el contrario, es un nativo que se convierte, prácticamente en un académico. Ambos tienen un prolongada envolvimiento en y compromiso con, la religión y conocen bien las preocupaciones nativas, pero las pueden relativizar, o al menos entender dentro ciertos contextos de desarrollo socio-histórico - para ellos es la dinámica social más que a la "tradición" o los "fundamentos" religiosos la base explicativa del estado actual de cosas.

Para el caso de Pernambuco, se aprecia también su conocimiento del candomblé (si por lecturas o experiencia personal, o ambos, no sé) y su utilización del mismo como referencia comparativa del batuque - pero nunca como una carencia o deturpación de la religión local respecto de la bahiana, sino apenas como dos evoluciones diferentes. Pernambuco sabe que el candomblé continúa siendo el "modelo" social y académico de una religión afrobrasilera de fuertes raíces africanas, y por ello destaca las diferencias del batuque respecto del mismo y describe sus rituales propios, resaltando su originalidad y su lógica específica. En el caso de la fala de los orixás batuqueros, que lo deja intrigado frente al más usual silencio de los orixás bahianos, despeja la duda recurriendo a los trabajos académicos que rescatando la opinión de Agenor Mirando Rocha, el último oluwo brasilero, señalan la "normalidad"

3 Invocar a nuestro querido, admirado y perspicaz antropólogo bahiano en cualquier contexto comparativo es, claro, una alta forma de elogio.

Debates do NER, Porto Alegre, ano i9, N. 35, P. 77-8 I, JAN./Jul. 20 i 9 
de este comportamiento. Es el conocimiento religioso - pero resguardado por académicos - lo que zanja la disputa - de nuevo, una buena combinación de ambas lógicas, la académica y la nativa.

El artículo sobre los mercados muestra, de nuevo, esta doble sensibilidad de su autor. Brinda una completa apreciación nativa de la importancia del mercado (expresada en términos de sociabilidad, de conveniencia económica, de pragmatismo ritual, pero también en términos teológicos, como lugar emblemático de la energía de Bará y como pieza clave en el paseo pos iniciático del batuque) y la combina con citas a una poca conocida pieza de Verger y Bastide sobre los mercados yorubas. Señala la relevancia del mercado en esas tierras africanas, y unas sutiles pero posibles "interferencias" africanas en la concepción arquitectural y en la distribución interna de las barracas del Mercado Popular de Porto Alegre. Con su vasta experiencia de vida como religioso y habitante de la ciudad, detalla transformaciones y permanencias y brinda un rico, profundo y multidimensional examen de la relevancia de este edificio histórico.

En fin, quienes no tuvieron el gusto y la fortuna de haber conocido personalmente a Adalberto Pernambuco Nogueira, Ojuobá y etnógrafo de oficio y corazón, deben agradecer a Debates do NER por disponibilizar estos pedazos de sabiduría y etnografía afro-gaúcha.

Recebido em: 07/04/2019

Aprovado em: 07/04/2019 
